\title{
CONSIDERAÇÕES SOBRE A CONCEITUAÇÃO DOS ESPAÇOS PÚBLICOS URBANOS
}

FANY CUTCHER GALENDER

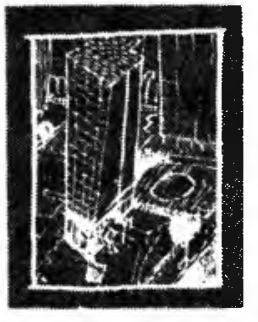

O presente trabalho pretende, a partir da análise de duas modalidades de espaços públicos urbanos (a praça e o parque), discutir a evolução dos espaços abertos de uso coletivo nas cidades. O ponto de partida foi a necessidade de compreensão do significado de ambos os conceitos, já que, gradativamente, vem se tornando bastante difícil a caracterização dos espaços públicos urbanos, devido à multiplicidade de expressões formais e espaciais das novas propostas, que permiteın uma percepção sensorial bastante variada e muitas vezes original.

Não se buscam definições definitivas, mas a análise de situações onde se mesclam referências, que, isoladamente, não permitem o entendimento global destes espaços. Vale lembrar, ainda, que a questão vem sendo tratada de maneira simplista, que remete a concepções limitadoras e ultrapassadas.

Assim sendo, considerarmos que a abordagem da questão só poderá se iniciar frente à leitura simultânea dos seguintes aspectos: o papel urbano do espaço analisado, sua relação com o entorno e com a estrutura espacial da cidade; sua inserção na paisagem que o gerou e sobre a qual atua; histórico e formação, com ênfase no aspecto funcional e formal, além de aspectos propriamente físicos tais como: porte, configuração espacial, localização e disposição, relação com o sistema viário, área de abrangência, relação entre escalas verticais e horizontais, visuais internas e externas.

Talvez a somatória destes itens nos permita entender os espaços existentes, fornecendo subsídios às discussões ligadas ao planejamento de novas estruturas espaciais urbanas, pois, como é freqüente, o estudo de aspectos isolados (isto é, somente, a evolução histórica ou físico-formal ou outros quaisquer), não tem possibilitado o aprofundamento conceitual do assunto, denotando uma defasagem entre teoria e prática, dada a velocidade com que esta última vem propondo novas soluções, ainda pouco compreendidas.

A praça poderia ser caracterizada fisicamente como uma manifestação espacial resultante da malha urbana e tradicionalmente presente desde a cidade 
medieval (ou mais remotamente, desde a ágora grega e o fórum romano), assumindo diversas formas de expressão, porém sempre produto de uma necessidade funcional mais ou menos evidente, de caráter civil, militar ou religioso. E o local de reuniões, notícias e intercâmbios. Convivem o mercado, os torneios e competições, as reuniões e as cerimônias públicas.

A ágora é o centro dos negócios e se define espacialmente pela construção progressiva de edifícios públicos e pórticos. Também o fórum romano é produto típico de uma arquitetura urbana, cercada por monumentos e estátuas, sendo o local onde se erguem os edifícios públicos mais significativos, agregando o mercado e os templos à vida cívica.

Segundo Lewis Munford (A Cidade na História, v. 1), as praças abertas da Idade Média, em cidades de crescimento orgânico, possuíam configuração irregular, em forma triangular, linear, oval, dentada, "aparentemente de forma arbitrária, porque as necessidades das edificações próximas tinham primazia e determinavam a disposição do espaço aberto" (p. 398). O mercado, os torneios e atividades religiosas ocupavam este espaço que, enquanto escala, se aproximava às dimensões humanas. Isto é, exceto pela catedral e por alguns edifícios cívicos de maior importância, o gabarito baixo e uma certa homogeneidade no tratamento das fachadas eram constantes. Na Idade Média, a praça é a expressão física da urbanização. As áreas vazias espalhadas entre os edifícios extremamente próximos são apropriadas para as atividades coletivas da cidade. Na Renascença, muitas destas atividades passaram a requerer edifícios especializados como por exemplo: o teatro.

As praças da Renascença caracterizam-se por remodelamentos artísticos das antigas praças medievais pela nova classe dominante. No entanto, as novas praças não unificam a cidade como a praça medieval fez, mas introduz um "enxerto" renascentista na cidade. Praça e estrutura urbana passam a adaptarse uma a outra.

A consciência estética sobrepõe-se fortemente sobre o aspecto funcional, derivada da tônica humanista do período. Perspectiva, tratamento das fachadas procurando uma unidade arquitetônica, além de observação estrita de proporções entre a praça e volumes do entorno são algumas das intençōes formais da Renascença.

No Barroco as praças são, inúmeras vezes, produto de planos estabelecidos por eixos de circulação ou pela intersecção destes eixos, ressaltando nos pontos focais infinitos caminhos. As formas são geométricas e a escala 
enorme. A renovação se dá com elementos decorativos como estátuas e fontes.

Em oposição à tendência da Renascença de incluir as edificações do entorno na intervenção, as praças barrocas abrem-se espacialmente para a cidade. São antíteses das praças da Renascença, voltadas para dentro (enclosed).

No Brasil, segundo Murillo Marx (Cidade Brasileira), a praça "deve sua existência, sobretudo, aos adros das nossas igrejas" (p. 50). Ou seja, somente diante de capelas, igrejas e conventos foram previstos espaços vazios, ressaltando as edificações do seu entorno. As funções públicas, via de regra, abrigadas em edificações alugadas, não contribuíram para o surgimento de praças, ao contrário da ocupação espanhola (Plaza Mayor ou a Plaza de Armas).

Enfim, são poucas as nossas praças cívicas e em menor número ainda as militares, que mantêm tais funções hoje em dia. Mesmo como origem é predominante a função religiosa, a presença da igreja ou da catedral na paisagem urbana.

Suscintamente, podemos perceber que o caráter marcadamente funcional da praça, que gera o espaço comunitário e por que não, a percepção da cidadania, foi evoluindo até o presente, alterando sua morfologia, seu papel na malha e na paisagem urbana e sua concepção, produto das diferentes posturas do urbanismo.

Em contrapartida, passa-se a uma rápida análise de outra possibilidade de apropriação do espaço público urbano, produto direto de uma nova situação político-econômica que evidencia uma nova função: o lazer e a recreação, não como mais uma das atividades humanas, mas como necessidade básica gerada pela divisão do trabalho e oriunda da industrialização e da urbanização acelerada de meados do séc. XIX.

Segundo Michael Laurie (An Introduction to Landscape Architecture), os espaços abertos tradicionais eram os mercados, os locais para a prática de esportes e cultos religiosos e sagrados, não existindo o espaço público para recreação não específica.

Somente em ocasiões especiais, quando uma propriedade privada era aberta ao público, as pessoas tinham oportunidade de ver jardins "plantados".

Na Idade Média, apesar da alta densidade urbana, a proximidade com o campo e a pequena escala das cidades fazem com que a recreação da população e as grandes concentrações ocorram nas escadarias das igrejas, nas áreas de mercados e praças. 
A partir da Renascença inicia-se a abertura eventual de jardins privados ao público. A Coroa e Nobreza passam a abrir seus portões ao povo, especialmente em Londres e grandes capitais européias. De acordo com Jellicoe (The Oxford Companion to Gardens), além dos espaços abertos acessíveis ao público, usualmente por graça ou favor real ou aristocrático, outras duas origens marcaram a criação dos parques: o Volksgarten, que a partir de uma teoria alemã, preconizava a necessidade de locais onde todas as classes sociais convivessem próximas à natureza, com edifícios contendo obras de arte voltadas à História, e o parque público propriamente, pertencente ao público como um direito e provido das facilidades que responderiam as solicitações das novas cidades em processo de industrialização.

Convém observar a existência de parques específicos (botânicos, horticultura), que não serão objeto de estudo devido à sua especificidade funcional acarretando uso restrito, apesar de reconhecermos a sua contribuição ao conhecimento científico das espécies, divulgando e consolidando a prática da jardinagem.

Com o aumento da população urbana, a arquitetura, basicamente palaciana e eclesiástica, passa a ter novos programas e exigências que despontam com a consolidação da nova classe burguesa emergente: surgem os teatros, escolas, óperas e bibliotecas. Esta mudança de programa acompanha a consolidação do capitalismo industrial.

Uma nova forma de percepção das condições de vida se implanta: noções de movimento (aumento do volume de circulação de mercadorias e pessoas) e multidão, alterando a vivência do tempo, da distância e, conseqüentemente dos espaços.

Surgem as ferrovias e rodovias trazendo novos contornos à Paisagem Urbana, através das novas edificações que abrigam as estações ferroviárias, as fábricas, habitações multifamiliares, além de novas formas de geração de energia. Um conjunto de novas demandas técnicas, funcionais e culturais associa-se a uma nova imagem visual para a cidade.

Neste contexto, desenvolvem-se, de maneira mais sistemática, propostas e movimentos ligados à implantação dos parques públicos. A ruptura com o espaço da aristocracia (Vilas Italianas), da nobreza (Versailles) e das grandes propriedades rurais (Inglaterra), traz uma nova adjetivação do espaço aberto urbano: o caráter público, que face ao aspecto predominantemente privado que tinha até então, dá novo significado à prática do profissional que atua na área da produção da Paisagem. É desta época (1840) a distinção entre "jardi- 
neiros". (landscape gardeners) e o que futuramente seria denominado "arquitetos da paisagem" (landscape architects).

No final da década de 60 do século passado, a maioria das grandes cidades da Inglaterra e França têm seus parques públicos. Inspirada em seu exemplo, a maior parte dos países europeus (exceto Alemanha), América Latina e algumas outras colônias seguem esta atitude, sem, no entanto, oferecer novas soluçōes de design.

Somente a partir do início do séc. XX é que o desenho dos parques (park design) se integra mais firmemente ao planejamento urbano, apesar de nos EUA, já no séc. XIX, nascer o conceito de Sistema de Parques com o movimento dos Parques Americanos (National Park Movement), remetendo aos nomes de Downing, Olmsted e Vaux.

As grandes áreas nas cidades passam a receber uso específico de recreação (Central Park/Nova York, Fairmont Park/Filadelfia, Parques de Chicago, Golden Gate Park, etc.) O início da prática de esportes organizados influi diretamente no programa de alguns parques.

Amplia-se a escala de intervenção: subúrbios, cidades-jardins, "The City Beautiful Movement", efetivando-se a integração das intervenções paisagisticas ao planejamento urbano, culminando com o sistema de parques suecos, exemplos em Berlim e Hamburgo na década de $20 \mathrm{e}$ as Novas Cidades Inglesas, após a Segunda Guerra Mundial, retomando, em muitos casos, as premissas das cidades-jardins.

A conceituação vigente no que se refere à abordagem de praças e parques faz com que, em realidade, a denominação empregada tenha caráter muitas vezes arbitrário e vinculado a uma imagem superada e, portanto, restritiva, na medida em que limita a leitura de novos fenômenos espaciais que ocorrem nas cidades. Mais importante ainda, $\epsilon$ o impedimento de um aprofundamento teórico e experimental por parte dos profissionais produtores e críticos dos espaços de uso coletivo.

$\mathrm{O}$ que distingue efetivamente uma praça de um parque? $\mathrm{O}$ raio de abrangência (seu caráter local, metropolitano ou regional? Comparar Parque do Ibirapuera e Praça da Sé, semelhantes neste aspecto); configuração espacial e dimensões (a reduzida área do Parque Trianon e as grandes dimensões da mesma Praça da Sé); a porcentagem de área verde face a porcentagem de área pavimentada e/ou construída, observando-se que alguns órgãos públicos estabelecem como norma para projeto de praças $20 \%$ de área pavimentada e $80 \%$ de área que definem os parques como "espaços abertos públicos caracte- 
rizados pela predominância de elementos naturais em sua composição e pela independência espacial com relação à malha urbana" (Rosa Kliass em "Planejamento dos Espaços Públicos: métodos, técnicas e documentação", Apostila ABAP), motivando a discussão sobre a questão da inserção da vegetação, da água e dos demais elementos naturais em meio urbano.

Ainda no que se refere às funções que abriga, à imagem que este espaço consolida na Paisagem Urbana e sua origem histórica, inúmeros são os pontos polêmicos, uma vez que qualquer abordagem que se detenha em alguns poucos pontos de análise, tenderá a falhar no estabelecimento de uma conceituação mais atual, tal a complexidade de situações e soluções que se apresentam.

A leitura detalhada do conjunto destes itens é fundamental para o entendimento dos espaços públicos urbanos em suas sutís nuances e variações. A evolução das cidades e sua configuração atual criaram novas demandas e respostas para estas questões que, globalmente, acabam por gerar novas paisagens e novos espaços que extrapolam o âmbito da mera definição.

A dinâmica da apropriação humana talvez seja um dos aspectos básicos para a revisão da tradicional caracterização dos espaços livres urbanos, pois a expectativa e a atuação efetiva do usuário reflete-se diretamente sobre o espaço, juntamente com a acelerada transformação da cidade, apoiando a redefinição dos espaços de uso coletivo.

Como entender La Villete, ou diversos outros parques temáticos, frente à conceituação de profissionais atuantes na área de paisagismo, como citado anteriormente. Como analisar que o Memorial da América Latina, onde predominam as edificações e os elementos construídos como o parque francês citado, agravado, no caso brasileiro, pelo total descaso no tratamento do espaço aberto. Que conseqüências trazem à paisagem de São Paulo as praças do metrô, marcas recentes de grandes intervenções espaciais em uma cidade que não tem controle sobre a produção de seu espaço. Como reduzir a discussão simplesmente a tópicos tais como escala, porte ou dimensões, considerando-se a existência dos "Pockets Parks".

Face às novas soluções espaciais que estão ocorrendo, acreditamos que a abordagem deva rever os pontos acima levantados (e outros mais), chegandose eventualmente a uma (ou diversas) modalidade de espaço público urbano, buscando-se sempre a compreensão global deste espaço no contexto da cidade que o abriga, superando-se pré-conceitos (e preconceitos) qualitativos e quantitativos que não têm servido à real situação que se apresenta. 
Cidades tão distintas como São Paulo e Tókio se assemelham através da unicidade técnica, tendendo à unicidade morfológica. A heterogeneidade é, muitas vezes, dada pelo envelhecimento dispar, já que a internacionalização do capital vem reduzindo as possibilidades de manifestação regional.

No entanto, este momento histórico, com seus produtos aparentemente definitivos que expressam as evoluções do capitalismo, atravessa um período de novas propostas formais e novas imagens, onde flexibilidade, mutabilidade e valorização do espaço (no nosso caso: o espaço livre urbano) são entendidos a partir da aceitação da cidade como um produto do homem e, portanto, da natureza, superando o pensamento reducionista que culminou em uma visão do meio urbano como o resultado mal acabado dos males da era industrial.

\section{SUBSÍDIOS PARA ANÁLISE:}

Elenco de alguns aspectos, conceitos e preconceitos que usualmente norteiam as discussões sobre o assunto.

PRAÇA

origem histórica

Funçōes:

mercado

culto (sagrado)

esporte (corridas, torneios)

político (cidadania)

manifestações espacial resultante da malha urbana;

dependência funcional

Relação com o Entorno:

se insere na cidade; é definida morfologicamente pelas edificações.

O espaço se abre para a cidade; relaciona-se com o urbano, constituindo-se um fato urbano.

Imagem Urbana:

espaço gerado pela cidade, aberto e inserido na mesma

continuidade espacial

Dimensōes:

predomínio do piso construído/pavimentação

menores se comparadas a um parque 


\section{PARQUE}

origem histórica

Função: lazer (ativo e passivo) como contraponto à sociedade industrial independência espacial com relação à malha urbana

Relação com o Entorno: se isola da cidade (acessibilidade, escala de abrangência: metropolitano, bairro vizinhança, etc.)

O espaço é contido em si mesmo, envolve mais o indivíduo, enquanto percepção espacial global

Imagem Urbana: "ilha" de amenização isolada, fechada para a cidade.

conjunto fragmentado com unidade

predomínio de elementos naturais em sua composição

dimensões: maiores, se comparadas a uma ou algumas praças urbanas.

\section{BIBLIOGRAFIA}

HARBERMAS, Juergen. Arquitetura Moderna e Pós-Moderna. Novos Estudos Cebrasp. São Paulo, set. 1987, n. 18.

JELLICOE, Sir Geoffren and Susan; Goode, P., Lancaster, M. The Oxford Companion to Gardens. . New York. Oxford University Press, 1986.

LAURIE, Michael. An Introduction to Landscape Architecture. U.S.A., Pitman Publishing Limited., 1976.

MARX, Murillo. Cidade Brasileira. São Paulo, EDUSP/Melhoramentos, 1980.

MUNFORD, Lewis. A Cidade na História. Belo Horizonte, Itatiaia Ltda., 1965. v. 1.

TOBEY, G.B. A History of Landscape Architecture. The Relationship of People to Environment. New York, American Elsevier Publisching Company, INC., 1973. 